\title{
Anatomical location and number of metastatic lymph nodes for prognosis of non-small cell lung cancer
}

\author{
Joji Samejima ${ }^{1}$, Hiroyuki Ito ${ }^{1}$, Takuya Nagashima ${ }^{1}$, Daiji Nemoto ${ }^{1}$, Daisuke Eriguchi ${ }^{1,2}$, \\ Haruhiko Nakayama ${ }^{1}$, Norihiko Ikeda ${ }^{2}$, Morihito Okada ${ }^{3}$ \\ ${ }^{1}$ Department of Thoracic Surgery, Kanagawa Cancer Center, Yokohama, Kanagawa, Japan; ${ }^{2}$ Department of Surgery, Tokyo Medical University, \\ Shinjuku-ku, Tokyo, Japan; ${ }^{3}$ Department of Surgical Oncology, Research Institute for Radiation Biology and Medicine, Hiroshima University, \\ Minami-ku, Hiroshima, Japan \\ Contributions: (I) Conception and design: J Samejima; (II) Administrative support: J Samejima; (III) Provision of study materials or patients: H Ito, H \\ Nakayama, N Ikeda, M Okada; (IV) Collection and assembly of data: All authors; (V) Data analysis and interpretation: J Samejima; (VI) Manuscript \\ writing: All authors; (VII) Final approval of manuscript: All authors. \\ Correspondence to: Joji Samejima. Division of Thoracic Surgery, National Cancer Center Hospital East, 6-5-1, Kashiwanoha, Kashiwa, \\ Chiba 277-8577, Japan. Email: jsamejima@east.ncc.go.jp.
}

\begin{abstract}
Background: The nodal classification of lung cancer is determined by the anatomical location of metastatic lymph nodes (mLNs). However, prognosis can be heterogeneous at the same nodal stage, and the current classification system requires improvement. Therefore, we investigated the correlation between the number of mLNs and prognosis in patients with non-small cell lung cancer.

Methods: Using a multicenter database in Japan, we retrospectively reviewed the records of patients who underwent complete resection for lung cancer between 2010 and 2016. Kaplan-Meier curves were used to determine recurrence-free and overall survival. Multivariate analyses were performed using the Cox proportional hazards model.

Results: We included 1,567 patients in this study. We could show a statistically significant difference in recurrence-free survival between $\mathrm{pN} 2$ patients with $1 \mathrm{mLN}$ and $\mathrm{pN} 2$ patients with $\geq 2 \mathrm{mLNs}(\mathrm{P}=0.016)$. Patients with a combination of $\mathrm{pN} 1$ ( $\geq 4 \mathrm{mLNs})$ plus $\mathrm{pN} 2(1 \mathrm{mLN})$ had a poorer prognosis than $\mathrm{pN} 1$ patients (1-3 mLNs) $(\mathrm{P}=0.061)$ and a better prognosis than $\mathrm{pN} 2$ patients $(\geq 2 \mathrm{mLNs})$ patients $(\mathrm{P}=0.007)$. Multivariate analysis showed that the number of mLNs was independently associated with cancer recurrence in patients with $\mathrm{pN} 1$ and $\mathrm{pN} 2$ disease $(\mathrm{P}=0.034$ and 0.018 , respectively).

Conclusions: Nodal classification that combines anatomical location and the number of mLNs may predict prognosis more accurately than the current classification system. Our study provides the concept that supports the subdivision of nodal classification in the upcoming revision of the tumor, node, and metastasis staging system.
\end{abstract}

Keywords: Non-small cell lung cancer (NSCLC); metastatic lymph nodes (mLNs); tumor, node, and metastasis classification (TNM classification); $\mathrm{N}$ descriptor

Submitted Mar 08, 2021. Accepted for publication May 27, 2021.

doi: $10.21037 /$ jtd-21-390

View this article at: https://dx.doi.org/10.21037/jtd-21-390

\section{Introduction}

Lymph node metastasis is one of the most significant predictors of prognosis in patients with non-small cell lung cancer (NSCLC) (1). The 8th edition of the tumor, node, and metastasis (TNM) classification of lung cancer has been the staging standard worldwide since January 2017.
The $\mathrm{T}$ and $\mathrm{M}$ descriptors were subdivided, whereas there were no major changes in the $\mathrm{N}$ descriptor (2). The $\mathrm{N}$ descriptor in lung cancer is currently determined solely by the anatomical locations of metastatic lymph nodes (mLNs), which have been identified using large-scale data analysis (1). Therefore, even the latest edition of TNM staging has 
failed to provide for the variability due to heterogeneity of the patient population. Several studies have demonstrated the usefulness of applying the number of mLNs (1,3-6), lymph node stations $(7,8)$, lymph node zones $(8,9)$, or lymph node metastatic ratios (10-12) to the nodal classification system to predict prognosis in patients with NSCLC. Multiple researchers have reported on the heterogeneity of prognosis at the same nodal stage, and the current $\mathrm{N}$ descriptor may have room for improvement $(3,4,6,10,11,13)$. In other carcinomas, such as colorectal, gastric, and breast cancer, the number of mLNs is considered in the $\mathrm{N}$ descriptor (14).

It is unclear whether the number of mLNs affects the prognosis of patients with NSCLC. Therefore, we conducted a retrospective study to answer this question using a multicenter database. We hypothesized that the prognosis would be poorer as the number of mLNs increased. The aim of this study was to investigate the correlation between the number of mLNs and prognosis in patients with NSCLC who had undergone complete resection.

We present the following article in accordance with the STROBE reporting checklist (available at https://dx.doi. org/10.21037/jtd-21-390).

\section{Methods}

\section{Patients}

Using a multicenter database (Kanagawa Cancer Center, Hiroshima University, and Tokyo Medical University), we retrospectively reviewed the medical records of 2,662 patients who underwent $\mathrm{R} 0$ resection for lung cancer between 2010 and 2016. Complete resection is defined as no residual tumor, either macroscopically or microscopically, at each institution. R0 resection includes complete resection and uncertain resection, which means that a dissection of three mediastinal and hilar-intrapulmonary nodal stations, so that the final specimen includes at least six lymph nodes, are not met. In our study, 69 cases met the above conditions (15). We excluded patients who underwent wedge resection/segmentectomy $(\mathrm{n}=711)$, had limited node dissection ( $n=273)$, were diagnosed with unclassifiable or small cell lung carcinoma $(\mathrm{n}=28)$, had an unknown number or station for lymph node metastasis $(\mathrm{n}=79)$, or died within 30 days after surgery $(n=4)$. Limited node dissection means ND0-1 without mediastinal lymph node dissection. In our study, the minimum number of lymph nodal stations is 6 .
However, the minimum number of lymph nodes is two, since the dissection area contains only fat and may not include lymph nodes. This study does not include patients with neoadjuvant chemotherapy. The tumor stage was determined according to the 7 th edition of the Union for International Cancer Control Tumor, Node, Metastasis classification for malignant tumors (16). All resected lymph nodes were classified based on the nodal map defined by the International Association for the Study of Lung Cancer (IASLC) (9). We collected clinicopathological variables, which included age, sex, smoking history, carcinoembryonic antigen (CEA), clinical stage, surgical procedure, lymphadenectomy, resected lymph nodes, metastatic lymph nodes, histologic type, pathological stage, pleural invasion, pulmonary metastasis, lymphatic vessel invasion, blood vessel invasion, EGFR mutation, adjuvant therapy, and prognosis. All cases were cT1a-4N0-2M0. The study was conducted in accordance with the Declaration of Helsinki (as revised in 2013). The study was approved by institutional review board of 24-18 and waived the requirement for informed consent from individual patients.

\section{Imaging and lymph node dissection}

Computed tomography (CT) images of the chest were acquired using a 16-row, multi-slice CT scanner with or without enhancement. The tumor size was estimated using high-resolution CT (HRCT) scans with a section thickness of 1-2.5 mm. Lymph nodes were defined as positive for metastasis if they had a short axis diameter $\geq 10 \mathrm{~mm}$ as measured by HRCT or if the uptake of fluorine- 18 fluorodeoxyglucose was greater than that of surrounding normal structures using positron emission tomography (PET) imaging. We performed PET imaging in all patients and endobronchial ultrasound-guided transbronchial needle aspiration (EBUS-TBNA) or mediastinoscopy if necessary to minimise the risk of undetected N2 disease. We performed systematic lymph node dissection for clinical N1 or N2 patients and lobe-specific lymph nodal dissection for clinical $\mathrm{N} 0$ patients. Systematic lymph node dissection was defined as dissection of the hilar lymph nodes and all ipsilateral mediastinal lymph nodes located at stations $2 \mathrm{R}, 4 \mathrm{R}, 7,8$, and 9 for cancers found on the right side and stations $4 \mathrm{~L}, 5,6,7$, 8 , and 9 for cancers on the left side (17). Lobe-specific lymph node dissection was defined as dissection of hilar lymph nodes and specific mediastinal lymph nodes depending on the location of the primary lung cancer (stations $2 \mathrm{R}$ and $4 \mathrm{R}$ for the right upper lobe, stations $4 \mathrm{~L}, 5$, and 6 for the left upper 


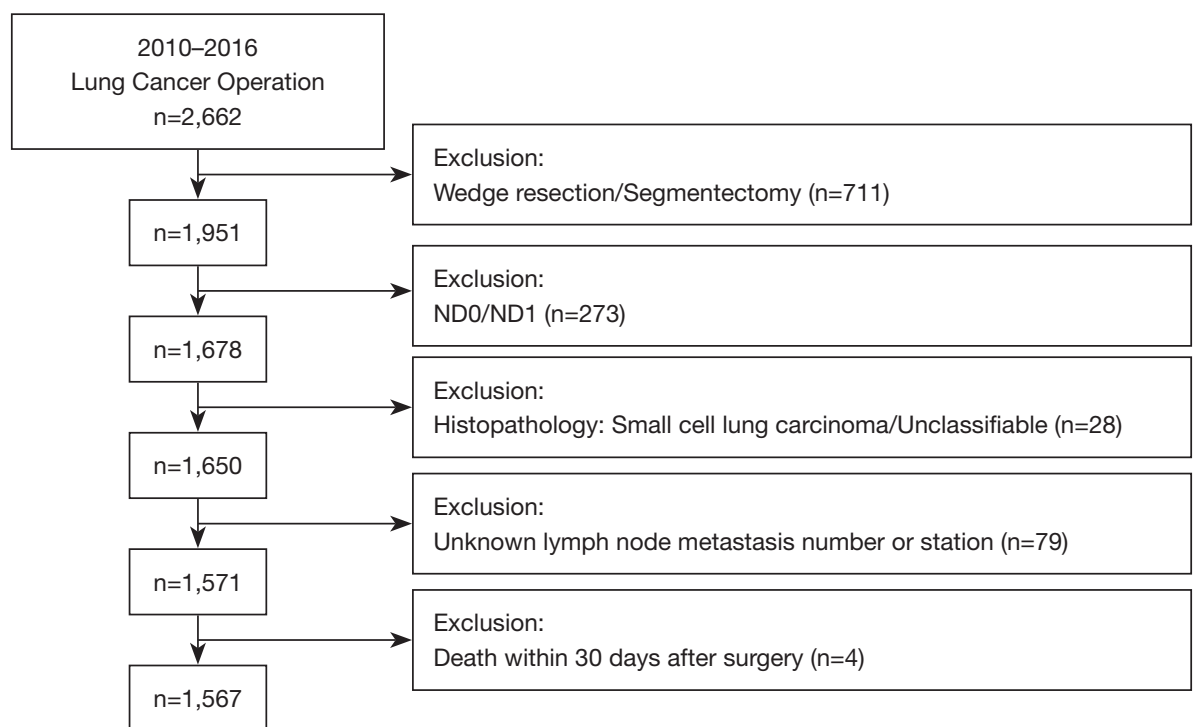

Figure 1 Flow diagram of patient selection in this study. ND, nodal dissection.

lobe, and stations 7,8 , and 9 for the lower lobe of each side).

\section{Follow-up}

All patients were followed up once every 3 months for the first 2 years and every 6 months thereafter. The followup examinations included a physical assessment, chest radiography, chest CT, and blood tests for the tumor marker carcinoembryonic antigen. PET and brain magnetic resonance imaging were performed in cases where the patient complained of neurological symptoms.

\section{Statistical analysis}

The date of recurrence was defined as the date that disease recurred and was confirmed by imaging. Confirmation of recurrence were determined either radiologically or histologically. Recurrence-free survival (RFS) was defined as the period beginning with surgery to the date of recurrence or the last known recurrence-free date. Overall survival (OS) was defined as the period beginning with surgery to the date of death (regardless of disease) or survival confirmation. Survival curves were plotted using the Kaplan-Meier method, and differences between groups were determined using the log-rank test. Multivariate analyses were performed using the Cox proportional hazards model. In the multivariable analyses, we included the covariate variables of age, sex, smoking history, histologic type, pathological $\mathrm{T}$ descriptor, and mLNs after checking for explanatory variables that are closely related to each other. Statistical analyses were conducted using SPSS software, version 23 (IBM, Armonk, NY, USA). All P values were two-sided, and values $<0.05$ were considered statistically significant.

\section{Results}

A total of 1,567 patients were analyzed in our study (Figure 1). Table 1 presents the clinicopathological characteristics of the patients. The median follow-up period was 49 months. We performed adjuvant chemotherapy in 500 patients $(31.9 \%)$. There were 326 recurrences, of which local recurrences were 168 cases and distant metastases were 145 cases (13 cases were unknown). The recurrence pattern of $\mathrm{pN} 1-2$ included 85 local recurrences and 88 distant metastases. The clinical $\mathrm{N}$ stages $\mathrm{cN} 0, \mathrm{cN} 1$, and $\mathrm{cN} 2$ were present in $84.0 \%, 12.0 \%$, and $4.0 \%$ of the patients, respectively. The pathological $\mathrm{N}$ stages $\mathrm{pN} 0, \mathrm{pN} 1$, and $\mathrm{pN} 2$ were present in $78.8 \%, 11.0 \%$, and $10.2 \%$ of the patients, respectively. Regarding pN2, upstaging of $6 \%$ from $\mathrm{cN} 2$ was observed. We performed systematic lymph node dissection in $16.7 \%$ and lobe-specific lymph node dissection in $83.3 \%$ of the patients. The median number of resected lymph nodes was 16 , and the median number of metastatic lymph nodes in patients with $\mathrm{pN} 1-2$ disease was 2. Regarding $\mathrm{pN} 1$, lymph node metastasis to hilar 
Table 1 Clinicopathological characteristics of the 1,567 patients

\begin{tabular}{|c|c|}
\hline Characteristic & Value \\
\hline Median follow-up period (months) & 49 \\
\hline \multicolumn{2}{|l|}{ Age (years), n (\%) } \\
\hline$<65$ & $516(32.9)$ \\
\hline$\geq 65$ & $1,051(67.1)$ \\
\hline Median age [range], years & 68 [20-93] \\
\hline \multicolumn{2}{|l|}{ Sex, n (\%) } \\
\hline Male & $910(58.1)$ \\
\hline Female & 657 (41.9) \\
\hline \multicolumn{2}{|l|}{ Smoking, n (\%) } \\
\hline Ever & $962(61.4)$ \\
\hline Never & $605(38.6)$ \\
\hline \multicolumn{2}{|l|}{ CEA, n (\%) } \\
\hline$\leq 5$ & $1,186(75.7)$ \\
\hline$>5$ & $381(24.3)$ \\
\hline \multicolumn{2}{|l|}{ Clinical T descriptor, n (\%) } \\
\hline $\mathrm{T} 1 \mathrm{a} / \mathrm{T} 1 \mathrm{~b}$ & $436(27.8) / 465(29.7)$ \\
\hline $\mathrm{T} 2 \mathrm{a} / \mathrm{T} 2 \mathrm{~b}$ & $481(30.7) / 95(6.1)$ \\
\hline T3 & $74(4.7)$ \\
\hline $\mathrm{T} 4$ & $16(1.0)$ \\
\hline \multicolumn{2}{|l|}{ Clinical $\mathrm{N}$ descriptor, $\mathrm{n}(\%)$} \\
\hline No & $1,316(84.0)$ \\
\hline $\mathrm{N} 1$ & $188(12.0)$ \\
\hline N2 & $63(4.0)$ \\
\hline \multicolumn{2}{|l|}{ Surgical procedure, n (\%) } \\
\hline Lobectomy & $1,550(98.9)$ \\
\hline Pneumonectomy & $17(1.1)$ \\
\hline \multicolumn{2}{|l|}{ Lymphadenectomy, n (\%) } \\
\hline Systematic lymph node dissection & $262(16.7)$ \\
\hline Lobe-specific lymph node dissection & 1,305 (83.3) \\
\hline Median resected lymph nodes & 16 \\
\hline Median metastatic lymph nodes in pN1-2 & 2 \\
\hline \multicolumn{2}{|l|}{ Histologic type, n (\%) } \\
\hline Adenocarcinoma & $1,216(77.6)$ \\
\hline Squamous cell carcinoma & $227(14.5)$ \\
\hline Others & $124(7.9)$ \\
\hline
\end{tabular}

Table 1 (continued)
Table 1 (continued)

\begin{tabular}{|c|c|}
\hline Characteristic & Value \\
\hline \multicolumn{2}{|c|}{ Pathological T descriptor, n (\%) } \\
\hline $\mathrm{T} 1 \mathrm{a} / \mathrm{T} 1 \mathrm{~b}$ & $413(26.3) / 383(24.4)$ \\
\hline $\mathrm{T} 2 \mathrm{a} / \mathrm{T} 2 \mathrm{~b}$ & $548(35.0) / 70(4.5)$ \\
\hline T3 & $138(8.8)$ \\
\hline T4 & $15(1.0)$ \\
\hline \multicolumn{2}{|c|}{ Pathological N descriptor, n (\%) } \\
\hline No & $1,234(78.8)$ \\
\hline $\mathrm{N} 1$ & $173(11.0)$ \\
\hline N2 & $160(10.2)$ \\
\hline \multicolumn{2}{|c|}{ Pleural invasion, $\mathrm{n}(\%)$} \\
\hline Present & $628(40.1)$ \\
\hline Absent & $939(59.9)$ \\
\hline \multicolumn{2}{|c|}{ Pulmonary metastasis, $\mathrm{n}(\%)$} \\
\hline Present & $58(3.7)$ \\
\hline Absent & $1,509(96.3)$ \\
\hline \multicolumn{2}{|c|}{ Lymphatic vessel invasion, $\mathrm{n}(\%)$} \\
\hline Present & $448(28.6)$ \\
\hline Absent & $1,119(71.4)$ \\
\hline \multicolumn{2}{|c|}{ Blood vessel invasion, n (\%) } \\
\hline Present & $628(40.1)$ \\
\hline Absent & $939(59.9)$ \\
\hline \multicolumn{2}{|c|}{ EGFR mutation, $\mathrm{n}(\%)$} \\
\hline Yes & $459(29.3)$ \\
\hline No & $675(43.1)$ \\
\hline Unknown & $433(27.6)$ \\
\hline \multicolumn{2}{|c|}{ Adjuvant therapy, n (\%) } \\
\hline Yes & $500(31.9)$ \\
\hline No & $1,067(68.1)$ \\
\hline
\end{tabular}

CEA, carcinoembryonic antigen; EGFR, epidermal growth factor receptor.

(\#10), interlobar (\#11), lobar (\#12), segmental (\#13), and subsegmental (\#14) was observed in 16 (9.2\%), 44 (25.4\%), $74(42.8 \%), 26(15.0 \%), 4$ cases $(2.3 \%)$, respectively ( 5 cases were unknown). There were significant differences in the 5-year RFS and OS rates between the pN0, pN1, and $\mathrm{pN} 2$ groups (the 5-year RFS rates for $\mathrm{pN} 0$, $\mathrm{pN} 1$, and 

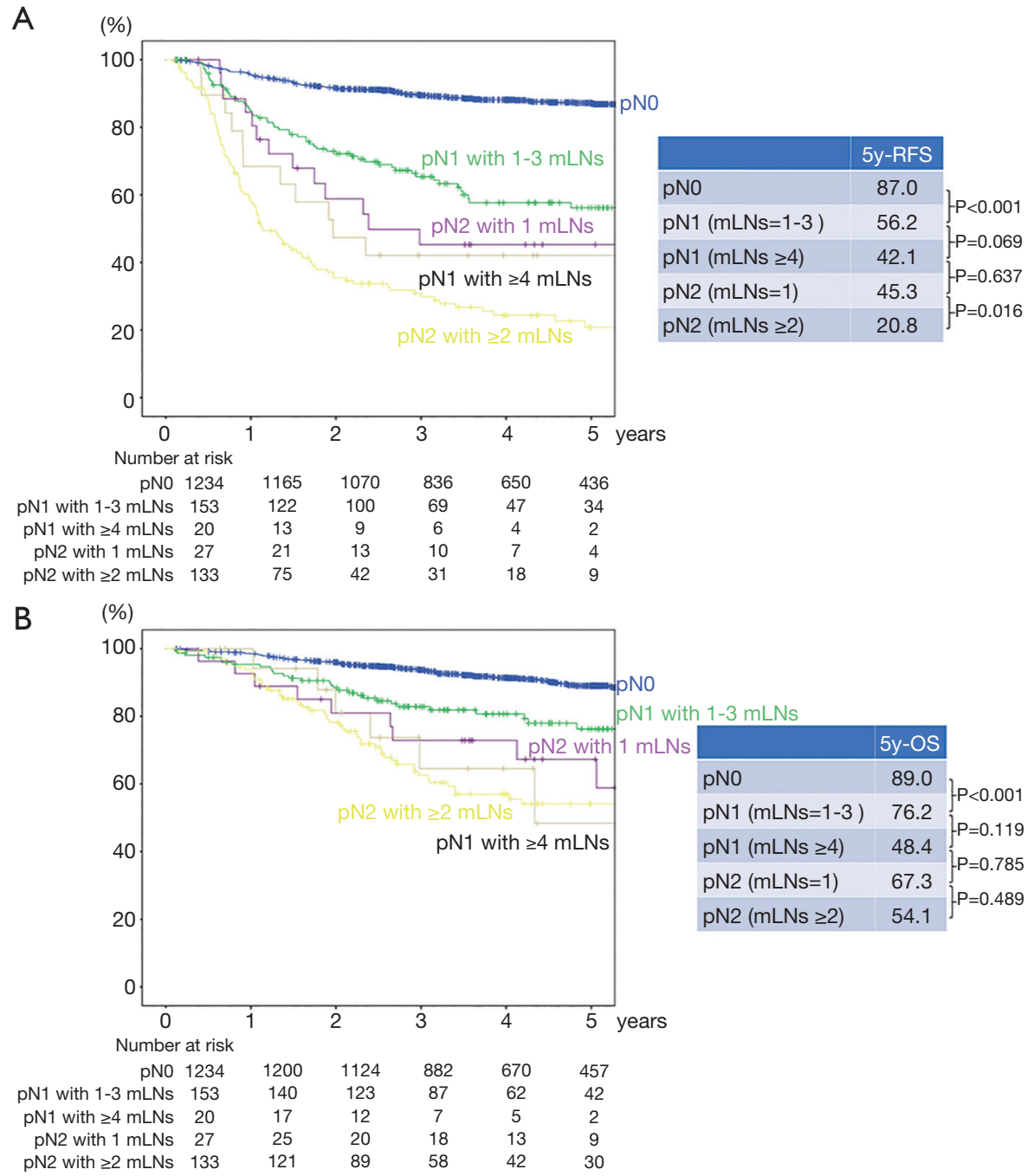

Figure 2 RFS (A) and OS (B) curves for patients with pathological nodal stages pN0, pN1 with 1-3 mLNs, pN1 with $\geq 4$ mLNs, pN2 with $1 \mathrm{mLN}$, and $\mathrm{pN} 2$ with $\geq 2 \mathrm{mLNs}$. Patients with $\mathrm{pN} 1$ disease and $\geq 4 \mathrm{mLNs}$ had a tendency for a poorer prognosis than pN1 patients with 1-3 mLNs, but no statistically significant difference was found between the two patient groups for RFS or OS. Patients with pN2 disease and $\geq 2 \mathrm{mLNs}$ had a tendency for a poorer prognosis than pN2 patients with $1 \mathrm{mLNs}$, and a significant difference was found between these groups for RFS. RFS, recurrence-free survival; pN, pathological node; mLNs, metastatic lymph nodes; OS, overall survival.

pN2 were $87.0 \%, 54.5 \%$, and $24.7 \%$, respectively, $\mathrm{P}<0.001$ and $\mathrm{P}<0.001$ for $\mathrm{pN} 0$ vs $\mathrm{pN} 1$ and $\mathrm{pN} 1$ vs $\mathrm{pN} 2$, respectively; the 5 -year OS rates for $\mathrm{pN} 0, \mathrm{pN} 1$, and $\mathrm{pN} 2$ were $89.0 \%$, $73.8 \%$, and $56.7 \%$, respectively, $\mathrm{P}<0.001$ and $\mathrm{P}=0.001$ for $\mathrm{pN} 0$ vs $\mathrm{pN} 1$ and $\mathrm{pN} 1$ vs $\mathrm{pN} 2$, respectively.) The RFS and $\mathrm{OS}$ curves overlapped each other for $\mathrm{pN} 1$ patients with 1,2 , and $3 \mathrm{mLNs}$ and survival was greater for these groups than for patients with 4-6 mLNs (Figure S1A,B). Consequently, we analyzed patients with $\leq 3 \mathrm{mLNs}$ and $\geq 4$ mLNs separately in the pN1 group. As shown in Figure 2, $\mathrm{pN} 1$ patients with $\geq 4 \mathrm{mLNs}(\mathrm{n}=20)$ tended to have a worse prognosis than those with $\leq 3$ mLNs $(\mathrm{n}=153)$; however, we could not show a statistically significant difference in RFS and OS. In patients with $\mathrm{pN} 2$ disease, those with $1 \mathrm{mLN}$ had a relatively good prognosis, and there were no differences between patients with $\geq 2$ mLNs. Accordingly, we analyzed patients with $1 \mathrm{mLN}$ and $\geq 2 \mathrm{mLNs}$ separately in the $\mathrm{pN} 2$ group (Figure S1C,D). Patients in the $\mathrm{pN} 2$ disease group with $\geq 2 \mathrm{mLNs}(\mathrm{n}=133)$ tended to have a worse prognosis than those with $1 \mathrm{mLN}(\mathrm{n}=27)$, and RFS was statistically significant. The numbers of patients with $\geq 4$ mLNs in the $\mathrm{pN} 1$ group and $1 \mathrm{mLN}$ in the $\mathrm{pN} 2$ group 


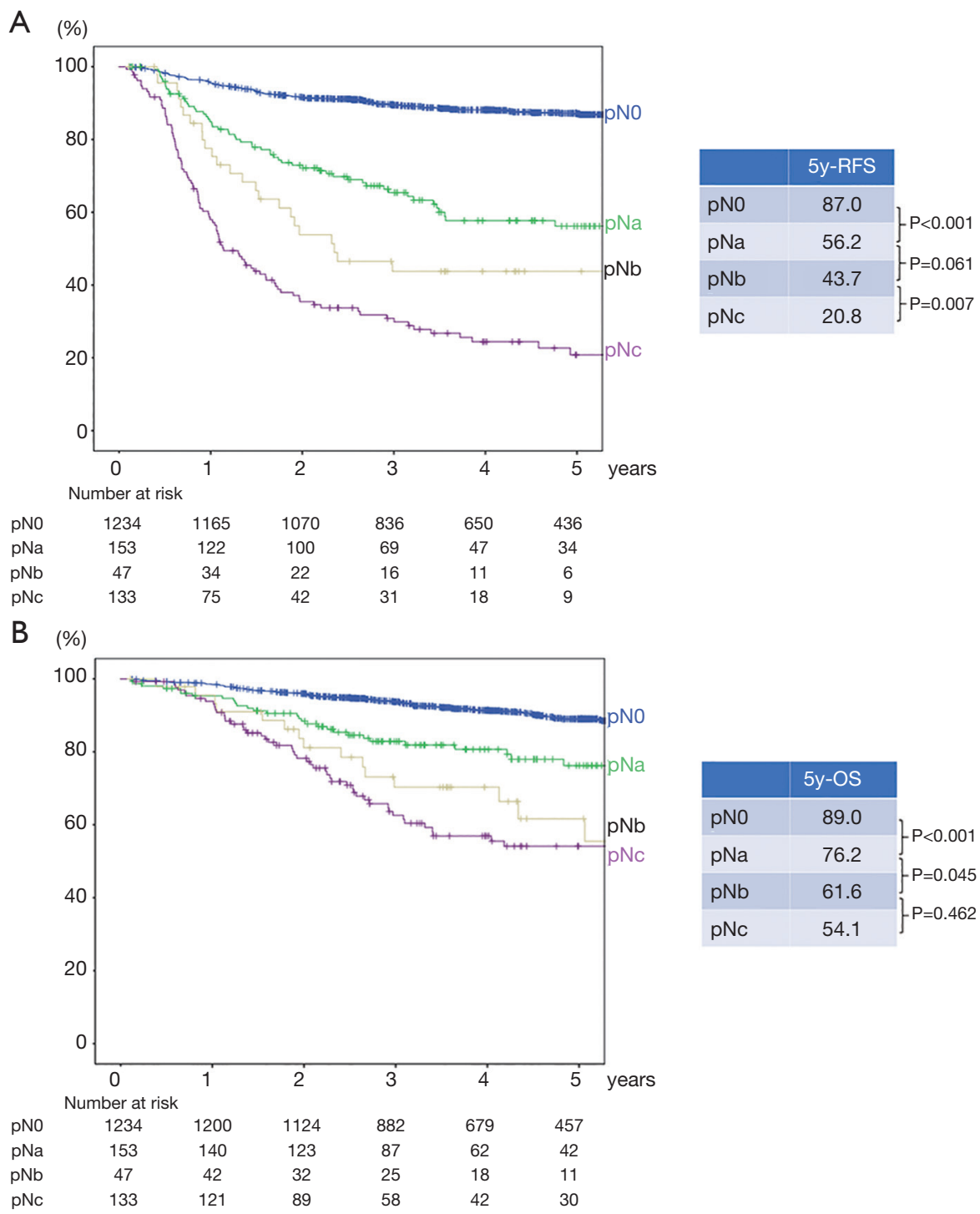

Figure 3 RFS (A) and OS (B) curves for patients with pathological nodal stage pN0, pNa, pNb, and pNc. pNa represents pN1 patients with 1-3 mLNs, pNb represents $\mathrm{pN} 1$ patients with $\geq 4 \mathrm{mLNs}$ plus $\mathrm{pN} 2$ patients with $1 \mathrm{mLNs}$, and pNc represents $\mathrm{pN} 2$ patients with $\geq 2$ mLNs. Patients in the $\mathrm{pNb}$ group had a poorer prognosis than $\mathrm{pNa}$, and a better prognosis than pNc. RFS, recurrence-free survival; pN, pathological node; mLNs, metastatic lymph nodes; OS, overall survival.

were small, but their RFS curves almost overlapped each other. Therefore, $\mathrm{pN} 1$ (mLNs $\geq 4)$ and $\mathrm{pN} 2(\mathrm{mLNs}=1)$ were analyzed as one group. In Figure $3, \mathrm{pNa}, \mathrm{pNb}$, and pNc represent the pN1 group with $1-3$ mLNs, $\mathrm{pN} 1$ group with $\geq 4 \mathrm{mLNs}$ plus $\mathrm{pN} 2$ group with $1 \mathrm{mLNs}$, and $\mathrm{pN} 2$ group with $\geq 2 \mathrm{mLNs}$, respectively. The $\mathrm{pNb}$ group had a worse prognosis than the $\mathrm{pNa}$ group, and a better prognosis than $\mathrm{pNc}$ group (Figure 3). Multivariate analysis showed that the pathological $\mathrm{T}$ descriptor and number of $\mathrm{mLNs}$ were independently associated with recurrence in patients with pN1 disease (Table 2). In patients with pN2 disease, only the number of metastatic nodes was independently associated with recurrence (Table 3).

\section{Discussion}

This study investigated the correlation between the number of mLNs and prognosis in patients with NSCLC 
Table 2 Multivariate analysis of RFS and OS in patients with $\mathrm{pN} 1$

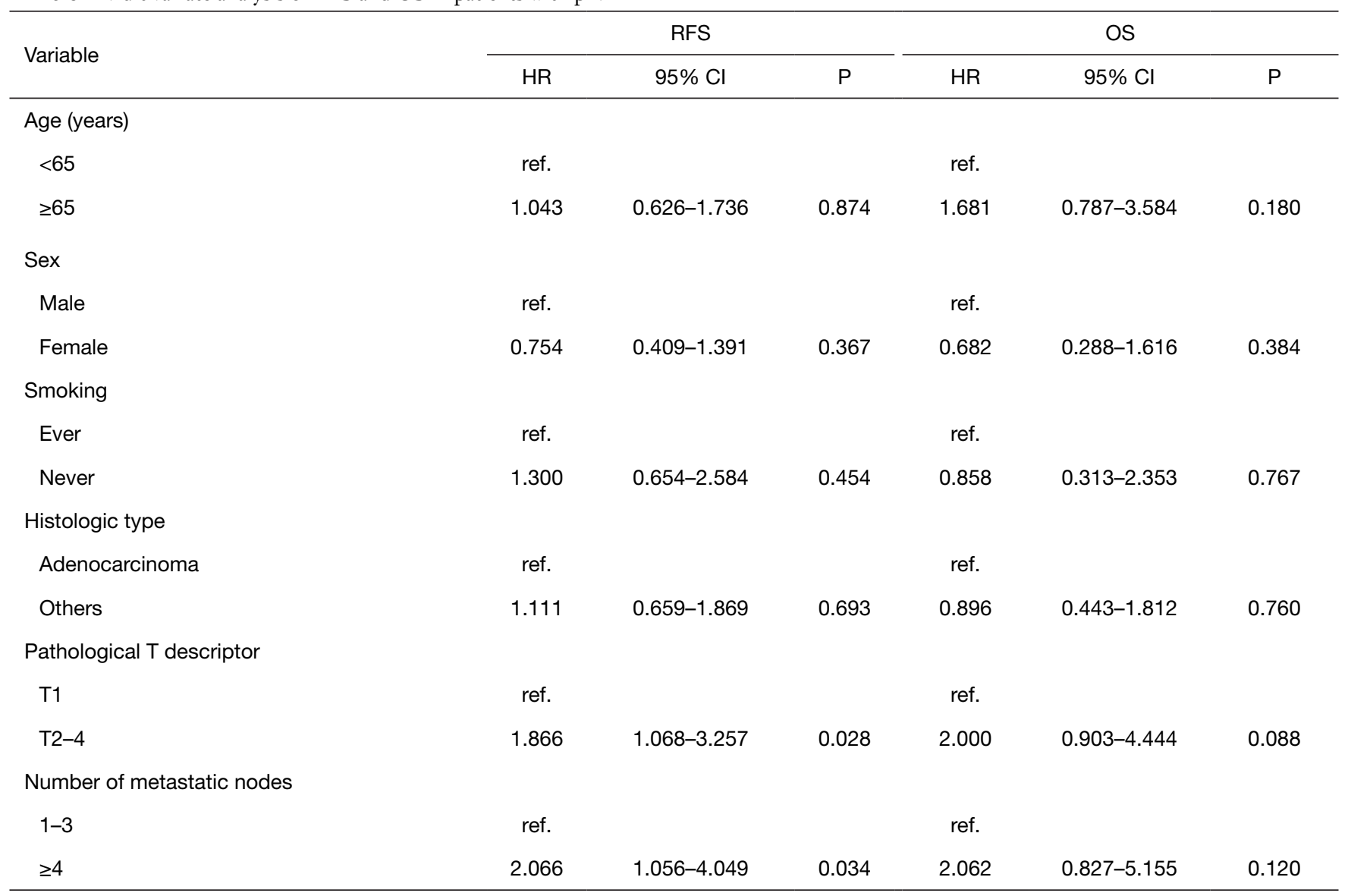

RFS, recurrence-free survival; OS, overall survival; pN, pathological node; HR, hazard ratio; Cl, confidence interval; ref., reference.

who underwent complete resection. We demonstrated that patients with 4 or more mLNs in $\mathrm{pN} 1$ disease and 2 or more mLNs in pN2 disease had a worse prognosis. By combining the anatomical location with the number of mLNs and dividing them into 3 groups, we found differences in survival rates between the groups. Our studies are the first to propose a new nodal stage that combines $\mathrm{pN} 1$ with $\geq 4 \mathrm{mLNs}$ and $\mathrm{pN} 2$ with $1 \mathrm{mLN}$. Our data show that subdividing the nodal classification system based on a combination of anatomical location and the number of metastatic lymph nodes may predict the prognosis of NSCLC.

In the current TNM classification, the $\mathrm{N}$ descriptor is still defined only by the anatomical location; however, this definition has some unsatisfactory aspects. The heterogeneity of prognosis at the same nodal stage is a problem that needs to be solved. Therefore, subdivision of the nodal stage has been proposed (1,3-10). In the lung cancer staging project of the IASLC, Asamura et al. concluded that the $\mathrm{N}$ descriptor in the 7th edition of the TNM classification accurately predicted prognosis, suggesting that the number and station of mLNs may affect prognosis (1). Our data is identical with the IASLC-proposed $\mathrm{N}$ staging system for $\mathrm{pN} 2$, but not for $\mathrm{pN} 1$. The point is that the anatomical location of mLNs is considered to be the most important factor in the nodal staging of lung cancer. Therefore, future subdivisions of the $\mathrm{N}$ descriptor will need to be combined with the current classification of anatomical locations to improve prognosis. Saji et al. reported that in patients with $\mathrm{pN} 1$ and $\mathrm{pN} 2$ disease, those with a number of $\mathrm{mLNs} \geq 4$ had a worse prognosis than patients with $1-3 \mathrm{mLNs}$, and their results regarding pN1 were identical to ours (3). Some previous studies reported that patients with a number of $m L N s ~ \geq 2$ had a worse prognosis than patients with $1 \mathrm{mLNs}$ in those with $\mathrm{pN} 1$ and $\mathrm{pN} 2$ disease $(1,6)$. In our study, 4 or more mLNs in $\mathrm{pN} 1$ and 2 or more mLNs in $\mathrm{pN} 2$ were the cutoff value 
Table 3 Multivariate analysis of RFS and OS in patients with pN2

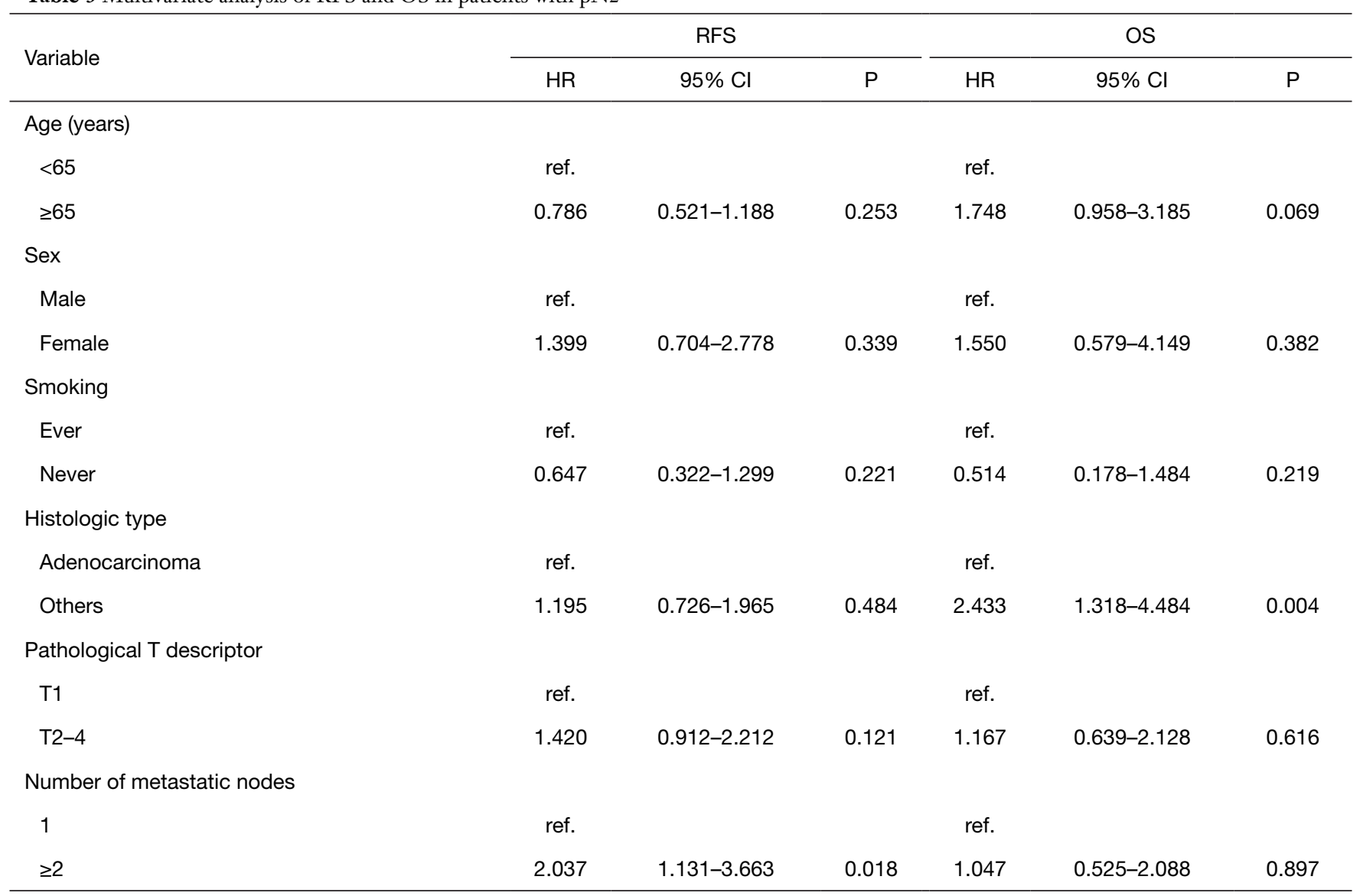

RFS, recurrence-free survival; OS, overall survival; $\mathrm{pN}$, pathological node; HR, hazard ratio; $\mathrm{Cl}$, confidence interval; ref., reference.

for each $\mathrm{N}$ descriptor. This may suggest that patients with $\mathrm{pN} 1$ and $\mathrm{pN} 2$ disease have different characteristics of lymph node metastasis. In other words, the extent of lymph node metastasis may be more important in patients with $\mathrm{pN} 2$ than $\mathrm{pN} 1$. The reason is that the $\mathrm{pN} 2$ group with $1 \mathrm{mLN}$ suggest skip N2 metastasis without N1 involvement, which indicates a good prognosis $(18,19)$. The $\mathrm{pN} 2(\mathrm{mLNs}=1)$ group is a different population in patients with $\mathrm{pN} 2$ disease, and the number of mLNs may be less important in the $\mathrm{pN} 2$ ( $\mathrm{mLNs}$ $\geq 2$ ) group. The fact that the number of mLNs did not affect the prognosis in $\mathrm{pN} 2(\mathrm{mLNs} \geq 2)$ group means that the anatomical location of mLNs (in other words, metastasis to the $\mathrm{N} 2$ region) is more important than the number of $\mathrm{mLNs}$ in $\mathrm{pN} 2$ ( $\mathrm{mLNs} \geq 2$ ) group. We propose a new nodal stage that combines $\mathrm{pN} 1$ with $\geq 4 \mathrm{mLNs}$ and $\mathrm{pN} 2$ with $1 \mathrm{mLN}$. Our study provides information that supports the specific subdivision of the $\mathrm{N}$ descriptor in the upcoming revision of the TNM staging system.
Multivariate analysis showed that the number of mLNs was independently associated with recurrence, but not with survival, in patients with $\mathrm{pN} 1$ and $\mathrm{pN} 2$ disease. In addition, we could not observe a statistically significant difference in OS between $\mathrm{pNb}$ (pN1 group with $\geq 4$ mLNs plus $\mathrm{pN} 2$ group with $1 \mathrm{mLNs}$ ) and $\mathrm{pNc}$ (pN2 group with $\geq 2 \mathrm{mLNs}$ ) (Figure 3). One of the reasons is that the number of cases in the $\mathrm{pN} 1(\mathrm{mLNs} \geq 4)$ and $\mathrm{pN} 2(\mathrm{mLNs}=1)$ groups was small. OS may be affected by treatment after recurrence. We should validate whether our new nodal stage shows a statistically significant difference in prognosis at each $\mathrm{T}$ stage, which requires a large number of patients. We believe that future large-scale studies could resolve this. In addition, multivariate analysis in Table 3 showed that patients with adenocarcinoma had a better prognosis than those with non-adenocarcinoma. The reason is that patients with adenocarcinoma have the opportunity to use new drugs such as tyrosine kinase inhibitor when they relapsed. In addition, 
patients with squamous cell carcinoma may be associated with interstitial pneumonia, and it may be difficult to receive effective treatment at the time of recurrence.

In clinical practice, patients with lymph node metastases will receive adjuvant chemotherapy. Therefore, it is difficult to compare $\mathrm{pN} 0$ with $\mathrm{pN} 1$ and $\mathrm{pN} 2$ without adjuvant therapy. If the number of lymph node metastases correlates with prognosis, we might need to change the management of the patients. For patients with a poor prognosis, we may consider performing more intensive chemotherapy or shortening the follow-up interval after surgery.

We acknowledge that our study has several limitations. First, because our study was retrospective, a validation cohort study will be required to support our results. Second, the numbers of lymph nodes were counted differently depending on whether the nodes were removed en bloc or separately (fragmented lymph nodes) (20). Lymphadenectomy methods were different for dissection or sampling according to the surgeon performing the work. Lymph nodes sometimes become one group, and the boundaries of individual nodes may not be recognized. Therefore, it may be difficult to accurately determine the number of mLNs. Third, systematic lymph node dissection was only performed for clinical N1 or N2 patients. In our study, the small number of systematic lymph node dissection may cause bias. The clinical trial Z0030 of the American College of Surgeons Oncology Group showed no survival difference between patients who underwent systematic lymph node dissection and mediastinal lymph node sampling for N0 or N1 NSCLC (21). There is also no unified recommendation for lymph node sampling between the guidelines $(17,22)$. The NCCN guideline recommend one or more nodes sampling from all mediastinal stations. It is unclear if there is no significant difference in prognosis between systematic and lobe-specific lymph nodal dissection. We conducted this study assuming that the prognosis of systematic and lobe-specific lymph nodal dissection is similar for patients with $\mathrm{cN} 0$. Fourth, the tumor stage was categorized according to the 7 th edition of TNM classification, not the 8 th edition in this study. There are no major changes in the $\mathrm{N}$ descriptor between the 7 th and 8th edition, therefore we consider that the results of the 7 th edition can be extrapolated to the 8th edition. Fifth, it is unknown whether our data can be applied to non-surgical cases, since our study only included patients who underwent surgical resection. It is difficult to recognize the number of mLNs using preoperative images. Therefore, it is unknown whether pathological stages can be applied to clinical nodal stages in lung cancer. Further investigation will be necessary using other datasets, including non-surgical patients.

In conclusion, our results suggest that nodal classification that combines subdivisions of the number of metastatic lymph nodes with their anatomical location may predict prognosis of NSCLC. Although American Joint Committee on Cancer (AJCC) recommended future subclassification of nodal stage that includes the number of lymph nodes (23), our study provides one concept to set nodal classifications in the upcoming revision of the TNM staging system. If the number of mLNs predicts prognosis, it is necessary to accurately diagnose the number of mLNs or to puncture multiple lymph nodes via EBUS or mediastinoscopy before surgery. This will help identify groups with poor prognosis and actively treat them. To clarify its prognostic impact, we need prospective large-scale data with a uniform patient background.

\section{Acknowledgments}

We would like to thank Editage (www.editage.jp) for English language editing.

Funding: None.

\section{Footnote}

Reporting Checklist: The authors have completed the STROBE reporting checklist. Available at https://dx.doi. org/10.21037/jtd-21-390

Data Sharing Statement: Available at https://dx.doi. org/10.21037/jtd-21-390

Peer Review File: Available at https://dx.doi.org/10.21037/ jtd-21-390

Conflicts of Interest: All authors have completed the ICMJE uniform disclosure form (available at https://dx.doi. org/10.21037/jtd-21-390). The authors have no conflicts of interest to declare.

Ethical Statement: The authors are accountable for all aspects of the work in ensuring that questions related to the accuracy or integrity of any part of the work are appropriately investigated and resolved. The study was conducted in accordance with the Declaration of Helsinki (as revised in 2013). The study was approved by institutional review board of 24-18 and waived the requirement for 
informed consent from individual patients.

Open Access Statement: This is an Open Access article distributed in accordance with the Creative Commons Attribution-NonCommercial-NoDerivs 4.0 International License (CC BY-NC-ND 4.0), which permits the noncommercial replication and distribution of the article with the strict proviso that no changes or edits are made and the original work is properly cited (including links to both the formal publication through the relevant DOI and the license). See: https://creativecommons.org/licenses/by-nc-nd/4.0/.

\section{References}

1. Asamura H, Chansky K, Crowley J, et al. International Association for the Study of Lung Cancer, A.B.M. Prognostic Factors Committee, I. Participating, The International Association for the Study of Lung Cancer Lung Cancer Staging Project: Proposals for the Revision of the N Descriptors in the Forthcoming 8th Edition of the TNM Classification for Lung Cancer. J Thorac Oncol 2015;10:1675-84.

2. Goldstraw P, Chansky K, Crowley J, et al. International Association for the Study of Lung Cancer, A.B. Prognostic Factors Committee, I. Participating, S. International Association for the Study of Lung Cancer, B. Prognostic Factors Committee Advisory, I. Participating, The IASLC Lung Cancer Staging Project: Proposals for Revision of the TNM Stage Groupings in the Forthcoming (Eighth) Edition of the TNM Classification for Lung Cancer. J Thorac Oncol 2016;11:39-51.

3. Saji H, Tsuboi M, Shimada Y, et al. A proposal for combination of total number and anatomical location of involved lymph nodes for nodal classification in non-small cell lung cancer. Chest 2013;143:1618-25.

4. Wei S, Asamura H, Kawachi R, et al. Which is the better prognostic factor for resected non-small cell lung cancer: the number of metastatic lymph nodes or the currently used nodal stage classification? J Thorac Oncol 2011;6:310-8.

5. Lee JG, Lee CY, Park IK, et al. Number of metastatic lymph nodes in resected non-small cell lung cancer predicts patient survival. Ann Thorac Surg 2008;85:211-5.

6. Katsumata S, Aokage K, Ishii G, et al. Prognostic Impact of the Number of Metastatic Lymph Nodes on the Eighth Edition of the TNM Classification of NSCLC. J Thorac Oncol 2019;14:1408-18.

7. Kang CH, Ra YJ, Kim YT, et al. The impact of multiple metastatic nodal stations on survival in patients with resectable N1 and N2 nonsmall-cell lung cancer. Ann Thorac Surg 2008;86:1092-7.

8. Yun JK, Lee GD, Choi S, et al. Comparison between lymph node station- and zone-based classification for the future revision of node descriptors proposed by the International Association for the Study of Lung Cancer in surgically resected patients with non-small-cell lung cancer. Eur J Cardiothorac Surg 2019;56:849-57.

9. Rusch VW, Asamura H, Watanabe H, et al. The IASLC lung cancer staging project: a proposal for a new international lymph node map in the forthcoming seventh edition of the TNM classification for lung cancer. J Thorac Oncol 2009;4:568-77.

10. Jonnalagadda S, Arcinega J, Smith C, et al. Validation of the lymph node ratio as a prognostic factor in patients with N1 nonsmall cell lung cancer. Cancer 2011;117:4724-31.

11. Ding X, Hui Z, Dai H, et al. A Proposal for Combination of Lymph Node Ratio and Anatomic Location of Involved Lymph Nodes for Nodal Classification in Non-Small Cell Lung Cancer. J Thorac Oncol 2016;11:1565-73.

12. Chiappetta M, Leuzzi G, Sperduti I, et al. Lymph-node ratio predicts survival among the different stages of nonsmall-cell lung cancer: a multicentre analysis. Eur J Cardiothorac Surg 2019;55:405-12.

13. Caldarella A, Crocetti E, Comin CE, et al. Prognostic variability among nonsmall cell lung cancer patients with pathologic N1 lymph node involvement. Epidemiological figures with strong clinical implications. Cancer 2006;107:793-98.

14. Union for International Cancer Control (UICC). In: Brierley JD, Gospodarowicz MK, Wittekind C, editors. TNM Classification of Malignant Tumours. 8th ed. Hoboken, NJ: Wiley-Blackwell; 2017.

15. Rami-Porta R, Wittekind C, Goldstraw P. Complete Resection in Lung Cancer Surgery: From Definition to Validation and Beyond. J Thorac Oncol 2020;15:1815-8.

16. Union for International Cancer Control (UICC) In: Sobin LH, Gospodarowicz MK, Wittekind C, eds. TNM Classification of Malignant Tumours. 7th ed. Hoboken, NJ: Wiley-Blackwell; 2009.

17. Lardinois D, Leyn PD, Schil PV, et al. ESTS guidelines for intraoperative lymph node staging in non-small cell lung cancer. Eur J Cardiothorac Surg 2006;30:787-92.

18. Wang L, Ye G, Xue L, et al. Skip N2 Metastasis in Pulmonary Adenocarcinoma: Good Prognosis Similar to N1 Disease. Clin Lung Cancer 2020;21:e423-34.

19. Tsitsias T, Okiror L, Veres L, et al. New N1/N2 
classification and lobe specific lymphatic drainage: Impact on survival in patients with non-small cell lung cancer treated with surgery. Lung Cancer 2021;151:84-90.

20. Zhong WZ, Liu SY, Wu YL. Numbers or Stations: From Systematic Sampling to Individualized Lymph Node Dissection in Non-Small-Cell Lung Cancer. J Clin Oncol 2017;35:1143-45.

21. Darling GE, Allen MS, Decker PA, et al. Randomized trial of mediastinal lymph node sampling versus complete lymphadenectomy during pulmonary resection in the

Cite this article as: Samejima J, Ito H, Nagashima T, Nemoto D, Eriguchi D, Nakayama H, Ikeda N, Okada M. Anatomical location and number of metastatic lymph nodes for prognosis of non-small cell lung cancer. J Thorac Dis 2021;13(7):4083-4093. doi: $10.21037 /$ jtd-21-390 patient with N0 or N1 (less than hilar) non-small cell carcinoma: results of the American College of Surgery Oncology Group Z0030 Trial. J Thorac Cardiovasc Surg 2011;141:662-70.

22. NCCN Clinical Practice Guidelines in Oncology. NonSmall Cell Lung Cancer (Version 4.2021). 2021. https:// www.nccn.org/professionals/physician_gls/pdf/nscl.pdf.

23. American Joint Committee on Cancer (AJCC) In: Amin MB, Edge S, Greene F, eds. AJCC Cancer Staging Manual. Springer; 2017. 


\section{Supplementary}

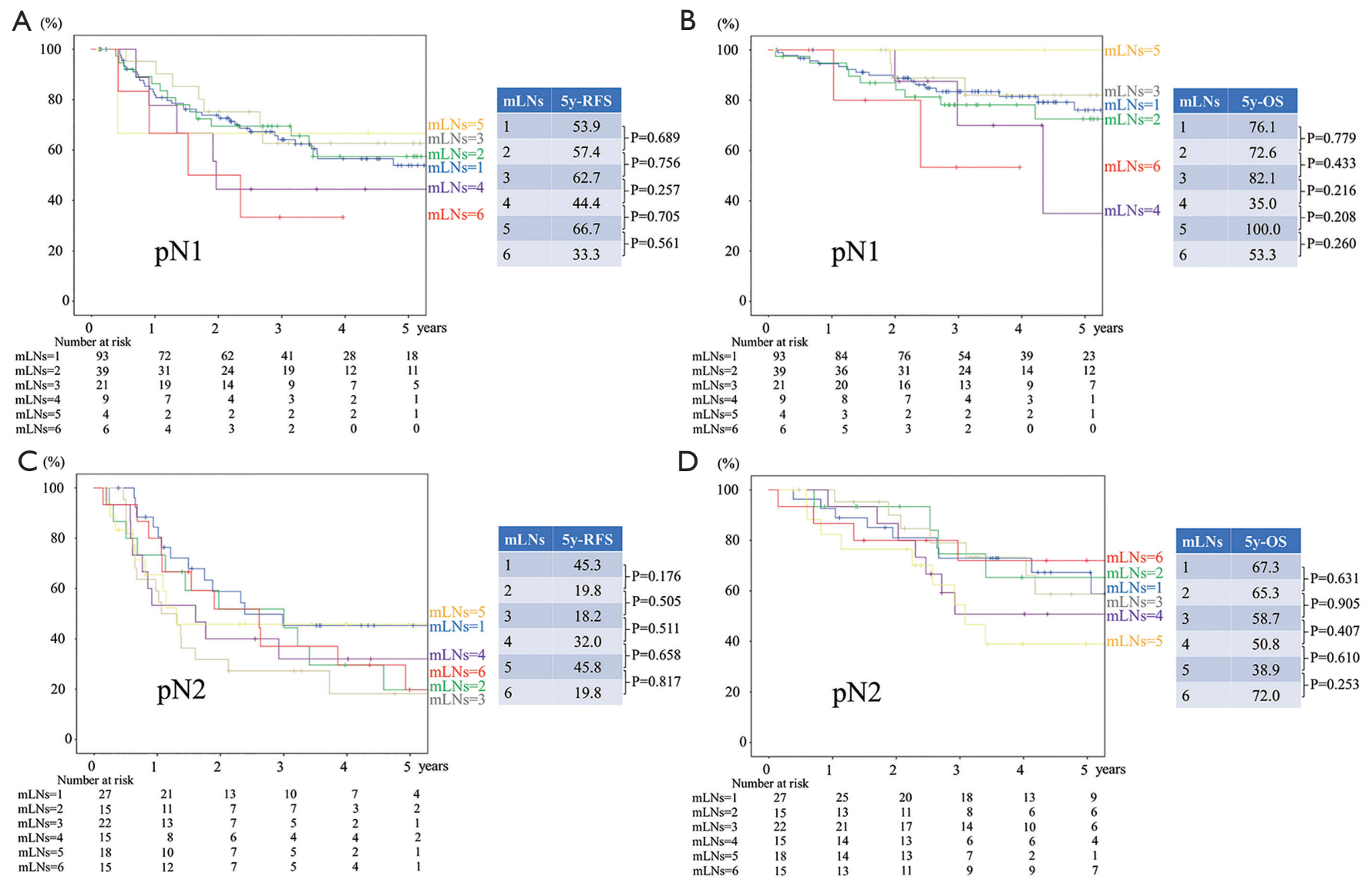

Figure S1 RFS (A) and OS (B) curves for patients with pN1 disease and 1-6 mLNs. RFS (C) and OS (D) curves for patients with pN2 disease and 1-6 mLNs. The RFS and OS curves for pN1 patients with 1, 2, and $3 \mathrm{mLNs}$ overlapped each other and fell below the curves for pN1 patients with 4-6 mLNs. In patients with $\mathrm{pN} 2$ disease, those with $1 \mathrm{mLNs}$ had a relatively good prognosis, and there was no difference in survival between patients with $\geq 2 \mathrm{mLNs}$. mLNs, metastatic lymph nodes; OS, overall survival; pN, pathological node; RFS, recurrencefree survival. 